\title{
English Translational Errors Encountered by Arab Natives
}

\author{
Islam Ababneh $^{1}$ \\ ${ }^{1}$ Department of Languages and Translation, Faculty of Education and Arts, University of Tabuk, Saudi Arabia \\ Correspondence: Islam Ababneh, Department of Languages and Translation, Faculty of Education and Arts, \\ University of Tabuk, Saudi Arabia. E-mail: iababneh@ut.edu.sa
}

$\begin{aligned} & \text { Received: November 19, } 2015 \\ & \text { Accepted: December 30, } 2015 \quad \text { Online Published: March 28, } 2016 \\ & \text { doi:10.5539/ijel.v6n2p118 }\end{aligned}$ URL: http://dx.doi.org/10.5539/ijel.v6n2p118

\begin{abstract}
This study aims to highlight errors in translating Arabic phrases and expressions into English. It is part of a research that attempts to establish some cultural connections between those translational mistakes and the embedded Arabic and Saudi religious and cultural factors that influence making such errors. To achieve the set goal, the researcher observed many written English signs around the city of Tabuk in a period of two years and then archived and analyzed the various translation mistakes collected from universities' announcements, religious flyers, hospital signs, bill board signs, shops and malls signs, personal signs...etc. The errors were classified into four categories: Singular/Plural, Sentence Structure and Syntax, Word Choice, and Spelling errors. Then a quiz was given to selected female English major students at the University of Tabuk; the quiz contained the same observed mistakes collected earlier. Therefore, the sample of the study was very diverse in its nature of Saudi Arabs and Arabs from other Arab countries that came to live and work in the city of Tabuk; while the students who took the quiz were all of Saudi nationality. It was concluded that the reasons Arab people who publish English translations fail to transfer the Arabic equivalence of English phrases and expressions are mainly due to literal translation and influencing cultural factors that make those people unfamiliar with the use of the right English words in their proper context.
\end{abstract}

Keywords: translation, cultural, expressions, Arabic/English, Saudi

\section{Introduction}

Transferring a message into another language is not an easy task since it needs more than just knowing vocabulary and language grammar to form sentences but depends on knowing the appropriate use of words within their correct cultural context. The content, style, idioms, and context is to be transferred from the source language into the target language; and the translator preferably should be an expert in a particular field to know the terms and vocabularies related to the specific field. Therefore, translation is more about transferring the meaning of sentences from one language into another language since word for word translation does not take into account the context, grammar, conventions, and idioms Newmark (1988) explained that cultural expressions can be found in proverbs, collocations, phrasal verbs and figures of speech including metaphors. He explained that foreign cultural expressions include ecological, material, and social cultures, social organizations expressions, political, religious, artistic, gestures and habits.

Gaber (2005) explained that culture-bound words can be translated using five different techniques:

- Cultural equivalence: words or phrases translated to their Arabic equivalence.

- Functional equivalence: words/phrases translated to the target language using the same function in the source language.

- Paraphrasing: word/phrase meaning is translated from the source language.

- Glossing: additional information is given in a footnote or within the text to explain the cultural word or expression.

- Borrowing: a word or phrase is borrowed from the source language and Arabize it.

The translation of Arabic words and expressions to English should account for the Arabic cultural context. However, not all researchers consider cultural aspects in translation. For example, Catford (1965) defined translation as simply the replacement of textual material in one language by equivalent textual material in another language. Newmark (1981) stated that translation is a craft consisting of the attempt to replace a written 
message and/or statement in one language by the same message and/or statement in another language. Also, Savory (1968) stated that translation is made possible by an equivalence of thought that lies behind its different verbal expressions.

On the other hands, many researchers have explained that culture is part of translation. Nida (1964) stated that the role of a translator is to facilitate the transfer of the message, meaning, and cultural elements from one language into another and create an equivalent response to the receivers.

Abdel-Fattah \& Zughoul (2003) studied how university English language learners use English collocations properly and render their meaning by having a sample of 16 graduate and undergraduate English students translate a two-form test (Multiple choice and free translation forms). The researchers concluded that the learners faced problems in translating collocations with cultural expressions in both translation tests.

Badawi (2008) investigated how 43 Saudi fourth years EFL teachers translated cultural phrases and expressions using a cultural bound expressions test and translation strategy awareness questionnaire. The study revealed a poor skills level of translating cultural expressions and wrong translation strategies by the students as most of them tended to give a literal translation of the phrases rather than giving any equivalent meaning.

Alousque (2009) studied the challenges in translating cultural items with different semantic range both in the source and target languages and the range of translation procedures used to explain their meaning through the analysis of the lexis from the French cultural domain of cooking. He concluded that there are some difficulties of translating those cultural lexis. The study has revealed that there are some constraints in the translation strategies used to transfer the meaning of cultural items into the target language (loan, functional equivalence, descriptive equivalence, approximate equivalence).

Dweik \& Abu-Shakra (2011) investigated the mistakes made by 35 M.A students from three Jordanian universities in translating religious texts from the Quran, Hadith, and the Bible. The researchers designed a translation test that consisted of 45 short sentences from the above religious texts. The students had problems in lexical and semantics collocations of items related to the Arabic culture. Also, the study revealed that there are disparities between Arabic concepts and metaphors as compared to Western ones.

\section{Method}

Unlike many researchers who adopted the technique of distributing a translation test with some phrases, expressions, and sentences to some sample of people then analyze the translational errors based on the results, this research is a compilation of various English translational errors collected by simply observing various publications and signs from various places in the Tabuk region, Saudi Arabia; followed by a quiz based on the collected material given to English major students to investigate the translational errors further. The signs originated from/posted on: shopping products, hospital departments, academic announcements, instructional signs, signs on houses, religious and cultural fliers and brochures. Therefore, the errors represent various segments in the society and the people's translational abilities are indication of cultural understanding of the English language since the errors were collected from various places and from different people in the society. The Arab sample of people who live in this region are tribal Saudi people of Arabic descents who have always lived in the Tabuk region or Saudi nationals who have come from other parts of Saudi Arabia to reside and work; the sample also includes other Arabic speaking expatriates who came to work in the Kingdom of Saudi Arabia from various other Arab countries; most of the people (Saudi and non-Saudi) have mostly lived in Arabic speaking countries and have rarely lived in western native English speaking countries.

In the first part of this work, the researcher observed, compiled, and organized a list of English translation errors that were printed or written on various establishments' signs within the city of Tabuk and the surrounding areas by simply touring the many parts of the city and photographing those signs in a period of two years. The signs were sometimes printed or hand written, some were old and others were relatively new, and some were permanently fixed on sign boards while some were temporarily posted for some event. Thus, the signs were written by various individuals or agencies and did not come from a single source. The errors were categorized into four types:

- $\quad$ Singular/Plural Errors: mix-up between using the singular and plural nouns.

- Sentence Structure and Syntax Errors: includes leaving a verb, possessive errors, wrong nouns, duplicate subject, incorrect word order, and clauses that do not belong together.

- Word Choice Errors: incorrect word use, connotation being off, substitution of antiquated forms for more common ones, using words together that do not typically appear with each other. 
- $\quad$ Spelling mistakes.

The second part of the research asked a sample of hundred students in the department of Languages and Translation at the University of Tabuk in their 3rd and 4th year levels to take a translation quiz that basically investigated the same observed errors: Singular/Plural, Sentence Structure and Syntax, Word Choice, and Spelling errors. The nationality of the students was Saudi and all of them had studied in the city of Tabuk for their elementary and secondary education in government or Saudi private schools but not in international schools. The quiz was given inside a classroom within the university campus and the students were given an ample time to write down their answers with their identities remaining anonymous. In designing the quiz, the same observed errors were tabulated and organized for the students to translate to find out how many of the students would make the same errors. The purpose of this part was to investigate whether English major students who have taken translation I, II subjects would make the same errors made by general people in the society. Two scores were given in each part of the quiz: score1 was for using the equivalent English word in its Arabic one while score2 was for using the correct English format of the word. For example, in the Singular/Plural section, translating the word "للعائلات" with "Family" or "Families" was accepted as correct for scorel but only "Families" was accepted as the correct plural translation. Similarly, in the Sentence Structure and Syntax part of the quiz, translating "الأحذية المخفضة" with "discount shoes" or "discounted shoes" was accepted as correct for score1 while only "discounted shoes" was accepted as the correct form of translation for score2.

\section{Results and Discussions}

It is known that Arab people in the Tabuk region in Saudi Arabia have only learned some skills of the English language in their secondary/primary school or rarely from some university English training courses; most of the people have not visited any native English speaking country. Therefore, the people's various publications in English indicate their translational skills; and the errors made reflect the people's lacked understanding of the various elements of the language. Based on the collected and observed translation material, people made mistakes in singular/plural nouns, sentence structure, and choosing the wrong cultural and religious English words for their equivalent Arabic phrases; for example, this was evident from many religious handouts given by staff at some Islamic centers and mosques. Tables 1-3 below detail examples of three types of translation errors collected and observed around the city of Tabuk categorized into three main caregories: Singular/Plural Errors, Sentence Structure and Syntax Errors, and Word Choice Errors.

Table 1. Singular/Plural errors-examples

\begin{tabular}{|c|c|c|}
\hline Arabic & English & Correction \\
\hline للعائلات فقط & Family only & Families only \\
\hline التقارير الطبية & Medical record & Medical records \\
\hline الحو ادث و الطو ارئ & Accident and emergency & Accidents and emergencies \\
\hline خدمة الزبائن & Customer Service & Customers Service \\
\hline الحو الات و الثيكات & Remittances and Draft & Remittances and Drafts \\
\hline
\end{tabular}

Table 2. Sentence structure and syntax errors-examples

\begin{tabular}{|c|c|c|}
\hline Arabic & English & Correction \\
\hline سوق ابو ريال & Every thing 1 Riyal & Everything is one Riyal \\
\hline الأحذية المخفضة & Discount shoes & Discounted shoes \\
\hline ق ق ق المم اليد و الاطفال & Infant's \&children's section & Infants \& Children section \\
\hline مركز العمليات و الموظفين & Operation center and employment & Operation and employment center \\
\hline القنسم النسائي & Ladie's section & Ladies section \\
\hline
\end{tabular}


Table 3. Word choice errors-examples

\begin{tabular}{|c|c|c|}
\hline Arabic & English & Correction \\
\hline سلامه المنشاة & Safety of origin & Establishment safety \\
\hline 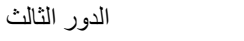 & Third round & Third floor \\
\hline 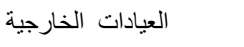 & Out patient department & Outpatient clinics \\
\hline قسم & Servise & Department \\
\hline البنك السعودي الهولندي & Saudi Hollandi Bank & Saudi Dutch Bank \\
\hline افخر انو اع الحلويات & I am proud types of Desserts & Finest kinds of sweets \\
\hline أنا لا أكل لحم الخنزير & I do not eat porker & I do not eat pork \\
\hline ما هي الوصفة الطبية & What is the Recipe & What is the prescription \\
\hline الى بوم الدين الدين & On the debt & Until day of judgment \\
\hline الوقوف على اسر اره & Stand on some of its secrets & Stop at some of its secrets \\
\hline المحور & Axis III & Theme III \\
\hline السور المكيه - الميه & Fence Meccan & Meccan verses \\
\hline اقتضت طبيعة البحث & Search warrant & The nature of the research required \\
\hline الجملة و اساليبها & Wholesale and methods & Sentence and its methods (Styles) \\
\hline ممنوع الوقوف امام المنزل & No parking hear & No parking here \\
\hline
\end{tabular}

The results of the quiz indicated a deeper problem of translation as the majority of the students could not give any translation to many words and phrases. Furthermore, there were mix-ups of using the singular nouns in place of plural nouns and vice versa. The sentence structure errors were classified into: dividing a single word into two, wrongly using possession (s), mixing verbs and nouns, and using wrong verbs and adjectives. Most problems in translations fell in the category of "wrong word choice" errors and are due to direct translation of vocabulary and improper word contextual understanding; some English to Arabic translations completely missed the right Arabic word for its equivalent English one; for example, Turkey was mixed between its use as a country or as a bird.

In the Singular/Plural part of the quiz, 58\% of the students picked the right equivalent English words for their Arabic ones but only $27 \%$ of those girl students used the correct singular/plural form. For example, all the students who attempted the quiz missed to give the correct plural translation form for the word "الحو ادث" and they gave only the singular form "emergency" in their translation. In the word "التقارير", many students missed to include the "s" letter that is indicative of plurality and gave only "report" as a translation. For two words phrase such as "الحوالات و الثيكات" many students missed to write two plural words and gave only one single and one plural translation or two single words while two plural words were expected for a correct answer. Similarly, for the two word phrase "خدمة الزبائن", majority of the students gave the singular translation of "customer" and not "customers" or the plural "services" instead of "service".

In the Sentence Structure and Syntax part of the quiz, 55\% of the students picked the equivalent English words for the Arabic words but only $11 \%$ of them gave the correct sentence structure translation. For example, many students translated the phrase "قصم المو اليد والاطفال" with possession as "infant's and children's section”. Similarly, many students translated the phrase "القسم النسائي "with "ladie's section" instead of "ladies section" while using

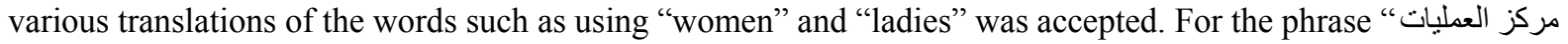
"some students mixed correct and wrong nouns in the translation such as "employ center and operation" or "center process" or "new born and children center" with some students misspelling some words such as "the senter employ and operation". Some students missed to give the full proposition phrases such using "front of" instead of "in front of". There were students who misplaced the nouns in a phrase or used the wrong nouns; for example, translating the phrase " للعائلات فقط "with "to families just" instead of "just for families"; also, some students translated the phrase "قسم المو اليد والاطفال" with "child and new birth section". There were problems of misusing the adjectives; for example, some students answered with "Saudian Holandi Bank" instead of using "Saudi Dutch Bank" in translating the term " البنك السعودي الهولندي". Also, some students did not include a verb or used more than one verb; for example, "no stop front of the house" or "I am could not eat meat" or "I am do not".

Most evident problems in translation were in the Word Choice section of the quiz. In marking this section, many translations of the given words were considered correct for score1 while only the very appropriate English translation was considered correct for score 2 . For the overall results, $46 \%$ of the students picked an acceptable English word or phrase while only about $23 \%$ of the students gave the very appropriate English equivalent for the Arabic words and phrases. For example, all the students missed to translate the word "الهولندي" to the correct English translation "Dutch" and many of them just gave the Arabic name of "Holandi". Similarly, most students did not answer with "verses" for the translation of the religious term "السور المكيه" and just gave the name 
"Meccan suras" instead. Likewise, some students translated the phrase " لدئ with "until day of Al-deen". Most students had problems with unfamiliar phrases and words; for example, all the students missed to correctly translate the word "المحور3". Also, few students gave a translation for "سلامه المنثاة" and only one student picked a suitable English word for "المنشاة"العيادات الخارجية". Furthermore, only one student translated the word" correctly to "outpatient clinics" even though many of these students would have visited hospitals and clinics; some students translated it with "foreign clinics" or "outside clinics" or "external clinics" or "outdoor clinics". Many students picked contextually not so appropriate words. For example, answering with a cooking phrase "what is the recipe" in translating the phrase "ما هي الوصفة الطبية"when something like "what is the medical prescription"

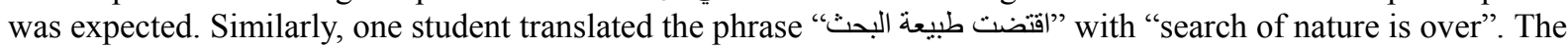
students were able to translate familiar phrases learned from courses in their curriculum; for example, all the students gave the correct translation for "الجملة و اسالييها" as "sentence and its styles". Some students knew to give relatively positive but not appropriate translations to positive words and phrases. For example, some students translated "البيت الانيق" with "nice house" or "beautiful home" or "classic home" or "unique home". Similarly, some students translated the phrase "with "great sweets" or "fancy sweets". Likewise, some students translated negative terms such as "ممنوع الوقوف امام المنزل "with relatively negative but not appropriate words such as "forbidden to stay in front of home". Many students translated religious terms with words that reflected their faith and understanding of the concept behind the term; for example, for the religious term " الى يوم" الدين", some students answered with "until final day", or "to religion day", or "the end of the world".

The Spelling mistakes observed on city signs were numerous; for example, one large shop sign showed the name "Elgant home" which misspelled the word "Elegant". Likewise, the students' spelling mistakes in all four sections of the quiz were plentiful; for example: "famely", "costomer", "custmer", "serves", "serrvec", "servese", "accedent", "acident", accedint", "acacedent", "midical", "midecin", "madecal", "traffac", "reboret", "typs", "thierd", "thered", "behiend", "securit", "Howes", "Safity", "floore", sentense, judjment, "Hom", "Safte", "Bilding", "Livel", "Dipartment", "Sekction". The spelling mistakes probably were caused by wrong pronunciation of words; i.e. using "hear" instead of "here" as this word is spoken and sounds the same to many Arab natives. Also, in pronouncing the word "medical" many Arabs would pronounce the word with different vowel letters instead of the "e" and "i" resulting in the wrong spelling of the word. Furthermore, many Arabs have problems in distinguishing between the "b" and "p" letters. For example, some students translated the word

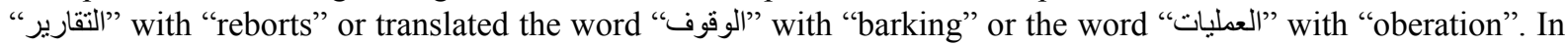
addition, some students chose wrongly similar looking words; for example, some students wrote down "customs" instead of "customers"; also, few students wrote down "incident" instead of "accident". The silent letters in words also give many Arabs problems in correctly writing words; for example, many students did not write the "g" in "judgment". Some students used common Arabicized English words in their translations. For example, some students translated the Arabic word "الثيكات" with "shakes".

Finally, it must be noted that the results of this study are only applicable to the region of Tabuk and cannot be necessarily generalized to other regions in the Arab world even though it gives some indications of the errors that Arab speakers make since this research is a general observation of a region where more than one Arab nationality live and work confirmed by Arab girls students who took a quiz that included the same observed mistakes.

\section{Conclusion}

It was evident from all the collected material that failures in translations committed by Arab natives are due to many reasons: lack of knowledge of appropriate English words, failure to achieve the English equivalence of cultural and religious Arabic terms, unfamiliarity with some English terms and names, unfamiliarity with proper sentence structures, and not distinguishing single from plural words. The quiz given to the girls students indicated a deeper issue of translation for the general Arab natives as many students made mistakes similar to the earlier observed errors on signs from around the city of Tabuk such as mixing singular/plural nouns, verbs and nouns mix-ups, inappropriate use of words, using Arabicized words, and making many spelling mistakes. The errors made in the word choice part of the quiz reflected some cultural and religious influences including the first language interference on Arab natives tendancy of picking inappropriate English vocabulary in translations.

\section{References}

Abdel-Fattah, H., \& Zughoul, M. (2003). Translational collocational strategies of Arab learners English. Babel, 49(1), 57-77.

Alousque, I. (2009). Cultural domains: Translation problems. Revista de Linguistica y Lenguas Aplicadas, 4, $137-145$. 
Badawi, M. (2008). Investigating EFL prospective teachers' ability to translate culture-bound expressions. Retrieved from ERIC database, (ED503396).

Dweik, B., \& Abu-Shakra, M. (2011). Problems of translating collocations in religious texts from Arabic into English. The Linguistics Journal, 5(1), 5-44.

Newmark, P. (1981). Approaches to translation. Oxford: Oxford University Press.

Nida, E. (1964). Toward a science of translating. Leiden: E. J. Brill.

Savory, T. (1968). The art of translation. London: Jonathan Cape Ltd.

\section{Copyrights}

Copyright for this article is retained by the author, with first publication rights granted to the journal.

This is an open-access article distributed under the terms and conditions of the Creative Commons Attribution license (http://creativecommons.org/licenses/by/3.0/). 